\title{
Prevalence and associated factors of stunting, underweight and wasting among children aged 6-23 months in Dalit and Non-Dalit: A cross sectional comparative study of Dhanusha district, Nepal
}

Anil Kumar Sah ( $\nabla$ kumaranil2065@gmail.com )

Nepal Health Research Council https://orcid.org/0000-0002-0480-6170

Rajan Paudel

Tribhuvan University Institute of Medicine

Madhu Dixit Devkota

Tribhuvan University Institute of Medicine

Ramesh Sigdel

Tribhuvan University Institute of Medicine

Research article

Keywords: Dalit, Non-Dalit, Stunting, Underweight, Wasting

Posted Date: January 10th, 2020

DOI: https://doi.org/10.21203/rs.2.20585/v1

License: (c) (1) This work is licensed under a Creative Commons Attribution 4.0 International License.

Read Full License 


\section{Abstract}

Background Nutrition asserts to be a fundamental for child growth and development. Undernutrition increases the risk of child morbidity and mortality becomes a major public health challenges in developing countries. The aim of study was to assess prevalence of stunting, wasting and underweight among children aged 6-23 months in Dalit and Non-Dalit and associated factors.

Method A cross sectional comparative study was conducted among mothers with their children aged 623months in Dhanusha district. Overall, 599 respondents were taken through multistage simple random sampling of which 300 from Non-Dalit and 299 from Dalit. Anthropometry measurement and interview were used for data collection technique and structure questionnaire was applied as a tool. Using Statistical Package for the Social Science, descriptive and inferential analysis were done.

Results Prevalence of stunting, underweight and wasting were $49.9 \%, 34.8 \%$ and $13.4 \%$ in Dalit and $39.0 \%, 25.0 \%$ and $8.7 \%$ in Non-Dalit respectively. Stunting was significantly associated with family type (AOR=1.93, 95\% Cl: 1.11-3.34) among Dalit while age of child (AOR=0.24, 95\% Cl: 0.10-0.57), ante natal care visit (AOR=3.20, 95\% Cl: 1.15-8.90) and media exposure (AOR=3.10, 95\% Cl: 1.11-8.64 in Non-Dalit. The underweight were significantly associated with age of child(AOR $=0.50 ; 95 \%$ of $\mathrm{Cl}$ : 0.27-0.93), knowledge on child feeding ( $A O R=2.00 ; 95 \%$ of $\mathrm{Cl}: 1.13-3.54)$ and media exposure (AOR=1.78; $95 \%$ of $\mathrm{Cl}$ : 1.01-3.14) in Dalit while media exposure (AOR=2.45; 95\% of $\mathrm{Cl}: 1.23-4.89)$ and duration of food sufficiency (AOR=2.51; $95 \%$ of $\mathrm{Cl}: 1.10-5.71)$ in Non-Dalit. The wasting were significantly associated with minimum meal frequency (AOR $=2.48 ; 95 \%$ of $\mathrm{Cl}: 1.04-5.93)$ in Dalit while birth interval $(\mathrm{AOR}=0.27 ; 95 \%$ of Cl: 0.08-0.92) in Non-Dalit.

Conclusion Prevalence of undernutrition got high in both groups. Family type in Dalit and age of child, knowledge on child feeding and media exposure in Non-Dalit were key factors of stunting. Age of child, knowledge on child feeding and media exposure in Dalit while media exposure and duration of food sufficiency were important factors of underweight. Minimum meal frequency in Dalit whereas birth interval in Non-Dalit were the major factors of wasting. Community based nutrition education, food security and health service utilization programme should help in reduction of undernutrition.

\section{Introduction}

Child nutrition becomes an essential to support in development, growth and survival among child[1]. Cognitive and physical development of the child get impaired by the undernutrition which increases the risk of the morbidity and mortality[2]. During golden 1000 days of life, greater than two-thirds child get victims of malnutrition which is due to inappropriate infant and young feeding practices[3].

Undernutrition such as stunting affects children development which leads to an irreversible and long-term effect on individual and society[4]. Undernutrition in children remains highly predominant in developing countries[5]. 
Undernutrition represents public health problem; 165 million children are stunted [6] and 51 million children among under five are wasted globally[7]. In Asia more than half and more than two-thirds of all under five were stunted and wasted respectively in 2017[7]. The trend of the stunting and wasting have declined over the previous few decades in Nepal[8, 9]. The high proportions of the children of this age still remain affected in Nepal which paves the way for a serious public health concern[1]. From the antique time in Nepal, "Dalit" were reflected as a schedule caste, untouchable and poorest[10]. In Nepal, Dalit is classified into two groups; Terai Dalit and Hilly Dalit[10]. Terai Dalit include Baantar, Chidimar, Dom and Halkhor Chamar/Harijan, Musahar, Dushad/Pasman, Tatma, Khatwe, Dhobi, whereas Hill Dalit includes Sarki, Badi, Gaine, Kami, Damai/Dholi, and Unidentified Dalits[10]. Population other than Dalit castes are known as Non-Dalits. In Nepal, the prevalence of stunting, wasting and underweight were $37.4 \%, 11.3 \%$ and $30.1 \%$ at National level while $41.6 \%, 17.0 \%$ and $40.7 \%$ at the central Terai region among children aged under-five respectively[11].

The golden 1000 days children considers to be as high risk groups of undernutrition. Inadequate child complementary feeding enhances stunting, which remains the key associated factors of stunting[5]. Similarly, socio-demographic; family types[12] age of child[13-15] maternal education[14-16] and knowledge on child feeding become associated with stunting. Likewise, socio-demographic; age of child[17-19], father education[20], and birth interval[18] and child illness[18-20] assert to be associated with underweight. Also, socio-demographic; age of child[17-19], mother education[18], father education[18] and media exposure[18] and child illness[20] are connected with wasting.

However, adequate nutrition becomes a precondition to achieve sustainable development goal[21]. Every child has a fundamental right for adequate nutrition[22]. Infant and young child feeding practices remain a priority program of the government with an aim to progress health and nutritional status[23]. The findings of the study would give a significant scenario of stunting, wasting and underweight of the district or similar settings which might be a baseline for the nutritional intervention. Thus, this study aims to assess the prevalence of stunting, wasting and underweight among children aged 6-23 months in Dalits and Non-Dalits and associated factors.

\section{Methods}

\section{Study design and setting}

The study was conducted between October 2016 and March 2017 in Dhanusha district, Nepal. The study method was cross sectional comparative. The Dhanusha as a district of the Nepal spoken commonly Maithili language covers the total area 1,180 square kilometers[24]. The south part of district is attached with the Bihar, India. The selected Village Development Committees (VDC) are about 5-30 kilometers East, North and South from headquarter (Janakpur).

\section{Study population, Sample size calculation and sampling procedure}


Children aged 6-23 months and their mothers became the study population living in that district. Two population proportion groups were used to calculate of the sample size[25]. The prevalence of minimum dietary diversity was taken as $20.1 \%$ and $31.32 \%$ of Dalit and Non-Dalit respectively[2]. By taking power $85 \%$, level of significance $5 \%$ and non-response rate $5 \%$, the sample size was 599 , where 299 from Dalit and 300 from Non-Dalit. Multi-stage simple random sampling was used in the study. Primarily, three out of seven electoral constituencies were selected and three VDCs were selected from each electoral constituency randomly. Finally four wards out of nine wards of each VDC were selected randomly by using lottery method. The selected VDC were Dhabauli, Panchaharba, Sonigama, Bahedabela, Fulgama, Nagaraen, Sinujoda, Sapahi and Shantipur. Vitamin A and immunization registers were applied for listing of the children aged 6-23 months. Moreover, the proportional allocation was reflected to estimate the number of children to participate in each selected ward. The young child was purposively selected in the case of more than a child. The mother who had 18 or above years were enrolled as a study participants. When mother-child pairs were not available during the data collection, two repeated visits were made.

\section{Data collection techniques, tools and procedure}

Pre-testing was accomplished among $10 \%$ of the respondents in Bateshwar VDC of the district. Nepal demographic health survey (NDHS) study tool was adopted[8] and the tool was modified in the local context. The questionnaire was translated to Maithili language to maintain the uniformity in the responses. The questionnaire of study was divided into socio-economic and demographic, health, child feeding and anthropometry and information of mother/family. Community Medical Assistants (CMA) were engaged as enumerators for data collection. Training regarding the overview of the study, ethical consideration, data collection technique and anthropometric measurements were given to field enumerators. Interviews (face to face) was accomplished with mothers by using structured questionnaire and child's height and weight were measured by recommended standard measuring instruments.

\section{Data quality issues}

For data quality, a day training was given to the enumerators. The training was focused on overview of the study, techniques of interview, data collection and ethical issues. Pretested tool was used and crosschecked each day was made for accuracy, completeness, consistency and clarity by the researcher.

\section{Data Safety and Security}

Monitoring and supervision was conducted by researcher himself during the data collection period. Collected data was stored in the safe place and password protected laptop was used for data entry and analyzed by one door system. 


\section{Data processing and analysis}

Collected data were coded, edited and entered into the EpiData 3.1 version. The entered data was transferred into SPSS 16.0 version for analysis. For anthropometry analysis, World Health Organization (WHO) anthropometry nutrition survey tool was used. Nutrition-related data were analyzed by using the WHO Anthro plus software 3.2.2 version. The Z-score of height-for-age (HAZ), weight- for- age (WAZ) and weight-for-height (WHZ) were calculated; HAZ, WAZ and WHZ less than -2 standard deviations (SD) was defined as stunted, underweight and wasted respectively.

Frequency and percentage were used to summarize the study variables in descriptive analysis. To find out association, a binary logistic model was used. P-value $<0.2$ of the variables in bivariate analysis were subjected to the multivariable analysis to control the possible effect of confounders[26]. Hosmer and Lemeshow Chi-square to see whether the model was fit. Enter method was applied to see the association between dependent and independent variables. The adjusted odds ratio (AOR) with $95 \%$ confidence interval was used to notify the strength of association, and $95 \% \mathrm{Cl}$ was used to declare the statistical significance in the multivariable analysis.

\section{Ethical consideration}

Institutional Review Committee of Institute of Medicine, Tribhuvan University, Maharajgunj approved the research proposal; each respondent was informed on the objective and method of the study, expected benefit. Mother who had 18 or above were participated and written informed consent applied, in case of illiterate thump print made before taking the interview. The confidentiality of the participants was maintained by using identifiable number.

\section{Results}

\section{Socio-demographic, economic and knowledge related characteristics}

Overall 599 respondents were taken, 300 from Non-Dalit and 299 from Dalit (Table 1). The mean age of children $(( \pm$ Standard Deviation, SD) were $14.4( \pm 4.6)$ months among Non-Dalit while $14.5( \pm 4.7)$ months among Dalit. The high proportion of children were male (55.7\%) in Non-Dalit whereas female $(56.9 \%)$ in Dalit. Most of the mothers were housewife (66.0\%) followed by agriculture (25.3) and were illiterate $(44.3 \%)$ in Non-Dalit while housewife (58.9\%) followed by labour $(24.1 \%)$ and were illiterate $(83.0 \%)$ among Dalit. The mother who had knowledge on complementary feeding and exposure to media were $51.8 \%$ and $58.9 \%$ among Dalit whereas $60.0 \%$ and $85.3 \%$ among Non-Dalit respectively. Most of the child father were illiterate (58.5\%) followed by some secondary level $(21.7 \%)$ among Dalit while secondary level (33.0\%) followed by illiterate (30.3\%) among Non-Dalit. Most of family had less than one year duration of 
food sufficiency in Dalit (96.0\%) and Non-Dalit (76.3). Most of the children were living in joint families in Dalit (74.9\%) and Non-Dalit (84.0\%).

\section{Nutrition and health related characteristics of children and their mother}

More than two third of the mothers were visited ante natal care (ANC) in Dalit (78.6\%) and Non-Dalit (88.0\%) (Table 2). About one-fifth of the children had child illness in past two weeks in both groups. More than two third of the children were having minimum meal frequency (MMF) practices in Dalit (71.9\%) and Non-Dalit (77.7\%). Similarly, more than half of the children were having minimum dietary diversity (MDD) practices in Dalit (55.9\%) and Non-Dalit (52.3\%). The prevalence of stunting, underweight and wasting were $49.9 \%, 34.8 \%$ and $13.4 \%$ in Dalit while $39.0 \%, 25.0 \%$ and $8.7 \%$ in Non-Dalit respectively.

\section{Factors associated with stunting among Dalit and Non-Dalit}

The result from the multivariable logistics regression analysis revealed that stunting were found significantly associated with type of family in Dalit (Table 3). The stunting was found 1.93 times more likely in the children living with single family as compared to the children living with joint family in Dalit $(A O R=1.93,95 \%$ of $\mathrm{Cl}: 1.11-3.34)$.

Similarly, the findings from the multivariable logistics regression analysis stated that stunting were significantly associated with age of child, media exposure and ANC visit in Non-Dalit (Table 4). The stunting was found protected among children aged 6-11 months than children aged 12-23 months in Non-Dalit (AOR= $0.24,95 \%$ of $\mathrm{Cl}: 0.10-0.57$ ). In addition, it was found that stunting was also found 3.10 times more likely among child mother who did not expose to media as compare to child mother who exposed to media in Non-Dalit (AOR=3.10, 95\% of Cl: 1.11-8.64). Furthermore, stunting was also 3.20 times higher in child mother who did not visit ANC than child mother who visited ANC in Non-Dalit (AOR= $3.20,95 \%$ of $\mathrm{Cl}: 1.15-8.90)$.

\section{Factors associated with underweight among Dalit and Non-Dalit}

The result from the multivariable logistics regression analysis revealed that underweight were found significantly associated with age of child, knowledge on child feeding and media exposure in Dalit (Table $3)$. The underweight was less likely among children aged 6-11 months as compared to 12-23 months in Dalit (AOR=0.50; $95 \%$ of $\mathrm{Cl}$ : 0.27-0.93). Furthermore, It was found that underweight was 2.0 times more likely among child mothers who had not knowledge on complementary feeding practices as compared to child mother who had knowledge on complementary feeding practices (AOR=2.00; $95 \%$ of $\mathrm{Cl}$ : 1.13-3.54). 
In addition, underweight was 1.78 times more likely among child mother who had not exposed to media as compared to the child mother who had exposed to media (AOR=1.78; $95 \%$ of $\mathrm{Cl}: 1.01-3.14$ ).

Similarly, the findings from the multivariable logistics regression analysis stated that underweight were found significantly associated with media exposure and duration of food sufficiency in Non-Dalit (Table 4). Underweight was 2.45 times more likely among the child mother who did not expose to media as compared to the child mother who exposed to media (AOR=2.45; 95\% of Cl: $1.23-4.89$ ) in Non-Dalit. In addition, it was found that underweight was 2.51 times more likely among the child family who had less than one year duration of food sufficiency as compared to the child family who had a year or more than a year duration of food sufficiency (AOR=2.51; $95 \%$ of $\mathrm{Cl}$ : 1.10-5.71) in Non-Dalit.

\section{Factors associated with wasting among Dalit and Non-Dalit}

The result from the multivariable logistics regression analysis revealed that wasting was found significantly associated with minimum meal frequency in Dalit (Table 3). The wasting was found 2.48 times more likely among child who did not meet minimum meal frequency as compared to children who meet minimum meal frequency in Dalit ( $\mathrm{AOR}=2.48 ; 95 \%$ of $\mathrm{Cl}$ : $1.04-5.93)$.

Similarly, the result from the multivariable logistics regression analysis revealed that wasting was found significantly associated with birth interval in Non-Dalit (Table 4). Wasting was found protected among child birth interval up to two years as compared to child birth interval above two years in Non-Dalit (AOR=0.27; $95 \%$ of $\mathrm{Cl}: 0.08-0.92$ ).

\section{Discussion}

This study findings revealed that the prevalence of stunting, underweight and wasting among children aged 6-23 months were 49.9\%, 34.8\% and 13.4\% among Dalit, while 39.0\%, 25.0\% and $8.7 \%$ among NonDalit respectively. The prevalence of severe stunting, underweight and wasting were $18.1 \%, 11.4 \%$ and $2.0 \%$ in Dalit whereas $12.0 \%, 4.0 \%$ and $2.0 \%$ in Non-Dalit. These proportions become higher than the finding from South Africa[27], Maldives[28] Sri Lanka[29], Ghana[30] and Nepal[9] Northwest Ethiopia[4], but it gets lower than India[31]. The findings of under-nutrition among Dalit became similar to the study findings of South Ethiopia[20]. This undernutrition findings got supported from the findings of province 2 of Nepal[9]. In Nepal, the trend of under-nutrition was decreasing from 1996 to 2016, but not satisfactory level[9]. The different in the prevalence of stunting, wasting and underweight in Dalit and Non-Dalit might be due to education of mother and father, knowledge on child feeding duration of food sufficiency and utilization of health services. Undernutrition increases risk of the child mortality as well as child morbidity and impair cognitive and physical development[2]. So this findings is also suggested that it remains a severe public health concern. 
The findings from the multivariable logistics regression analysis stated that stunting were not significantly associated with birth interval, family type, fathers' education, household owning agriculture land, mothers' occupation, and place of delivery in Non-Dalit. The study reveals that the stunting got protected among children aged 6-11 compared to 12-23 months in Non-Dalit. This result was in line with a study conducted in Ethiopia[32] and Indonesia[33]. This result got reinforced by the result of somewhere else[34]. Similarly, the findings showed that the underweight was also protected among 6-11 months as compared to 12-23 months in Dalit. The findings got supported from the study of Pakistan[17], Indonesia[35]. Undernutrition is less among children younger than six months because child nutrition depends upon the breastfeeding[36]. In Nepal, some of the children got breast milk a year by their own mother[37]. In this age, the practices of child feeding remain the major contributor to undernutrition[36, 38].

The result from the multivariable logistics regression analysis revealed that stunting were not found significantly associated with timely initiation of complementary feeding, media exposure, knowledge on child feeding and ANC visit in Dalit. This study findings stated that the stunting were more likely among children living with the nuclear family than joint family in Dalit. The findings of study got reinforced from the study conducted in Nepal[39] and Kenya[40]. An approximately one-fourth of the child mothers $(24.1 \%)$ were working as a daily wage/labor among Dalit. At the time, mothers might not be able to care properly to their children. Those mothers who were working in the field setting were keeping with them were not feeding frequently, which might affect on feeding practices of the child[37]. Children are not living in a single family who get appropriate care by someone (for example-grand-parents) during busy of her/his mother.

This result indicated that stunting was more likely among mother who did not visit ANC than mother who visited ANC in Non-Dalit. This result gets reinforced by a study conducted in Indonesia[33].

Recommended ANC visit might support to improve knowledge regarding appropriate feeding practices of the child and got a chance to proper counseling regarding child nutrition and utilization of health services, resulting optimal feeding of the child and decreases undernutrition.

The findings of study showed that stunting was more likely among mother who did not expose to media than mother who exposed to media among Non-Dalit. This result got reinforced by the findings of Bangladesh[41]. Similarly, the findings stated that underweight was more likely among mother who did not expose to media as compared to mother who expose to media among Dalit and Non-Dalit. Different studies showed that inadequate feeding practices were significantly associated among the mothers who have limited exposure to media, which means positive effect of media on child feeding[42, 43]. Media might be as an effective for promoting child feeding practices[42] and also enhance knowledge on health and nutrition of the child. Furthermore, it might help in reduction of under-nutrition among children[41].

The result from the multivariable logistics regression analysis revealed that underweight were not found significantly associated with family type, household owning agriculture land, father education, main source of family income, minimum acceptable diet (MAD), MDD and child illness past two weeks in Dalit. 
The findings indicated that the underweight was more likely among child mother who did not have knowledge on child feedings as compared to mother who have knowledge on child feeding in Dalit. This findings got reinforced from the results of Nigeria[44]. Lack of the knowledge among mother was a key barriers for adequate child feeding practices $[43,45]$. In addition, this study showed secondary and above level maternal education was very low (11.7\%). Appropriate complementary feeding practices such diversified food and minimum acceptable diets were associated with child under-nutrition[6]. It shows lack of information regarding dietary diversity as well as frequency of nutrient taking practices. So, maternal awareness and education help to improve nutritional status among children by improving knowledge on child feeding[13].

The result revealed that underweight was more likely among the family with less than a year duration of food sufficiency as compared to the family with a year or more than a year duration of food sufficiency. The findings of a study state that food insecurity is associated with underweight in Iran[46]. The families having sufficient food might feed adequately to their children. The findings revealed that wasting was found less likely among children having birth interval up to two years as compared to children having birth interval above two years among Non-Dalit. This findings became contrast with a study conducted Ethiopia[47]. The proportion of wasting was high among children 24 months while it is not significant[48]. The evidence showed that lower the birth interval is higher risk of mortality and morbidity[49, 50]; but not all[51]. When mothers get feed elder child and at the same time they also feed younger, therefore wasting might be protected among children with birth interval up to two years.

This findings of study showed that wasting was more likely among children who were not recommended minimum meal frequency as compared to child who got recommended MMF among Dalit. This findings got supported from the result of Ethiopia[47] and Indonesia[35]. This study revealed that about one-fourth of the Dalit child mother were daily wages/labour. The mothers who were working in the field setting and keeping a child did not feed frequently[37]. Similarly, only two-fifth of Dalit child mother had an appropriate knowledge on child feeding practices. Inappropriate knowledge among mothers was an important barriers for adequate complementary feeding practices[43, 45]. Likewise, only one-tenth of the Dalit mothers had secondary and above education. Some of the findings of study showed that mother education was associated with inappropriate child feeding practices[52] and wasting[18]. So, appropriate child feeding practices could help in reduction of undernutrition.

This cross sectional comparative study demonstrated the prevalence and associated factors of stunting, wasting and underweight for Dalit and Non-Dalit. Obviously, the study is not free from the some of the limitation. The questions related socio-economic, health, knowledge and complementary feeding practices were not observed, based on the mother response which might be affected by recall and social desirability bias.

\section{Conclusion}


The study revealed that the prevalence of stunting, underweight and wasting got higher in Dalit than NonDalit children. These become higher than the national figures[9] and also higher than those countries who have better indicators of the health. So, undernutrition remains the severe public health concerns in Dalit and Non-Dalit. Type of family among Dalit and age of child, media exposure and ANC visit among NonDalit were a key associated factors of the stunting. Similarly, age of child, mother knowledge on child feeding and media exposure among Dalit and media exposure and duration of food sufficiency among Non-Dalit were an important associated factors of the underweight. Likewise, minimum meal frequency among Dalit and birth interval among Non-Dalit were the significant factors of wasting.

So, the findings of study confirms that there is plenty of the ways for reducing undernutrition among children in Nepal. It would be better to focus these key factors for reducing stunting, wasting and underweight. To reduce undernutrition, mothers' nutritional education, food security, and increasing access and utilization of the health services would be better to recommend.

\section{Abbreviations}

ANC: Ante natal care; AOR: Adjusted odds ratio; Cl: Confidence interval; CMA: Community medicine assistant; COR: Crude odds ratio; HAZ: Height for age; MAD: Minimum acceptable diet; MDD: Minimum dietary diversity; MMF: Minimum meal frequency; NDHS: Nepal demographic health survey; SD: Standard deviation; SPSS: Statistical package for social sciences; VDC: Village development committee; WAZ: Weight for age; WHO: World health organization; WHZ: Weight for height.

\section{Declarations}

\section{Acknowledgements}

We would like to express gratitude to mothers and their children for their willingness to participate in the study. We would also like thank Female Community Health Volunteers, Health Post in charges, District Public Health Offices Dhanusha, enumerators, families of the author who support directly and indirectly and Department of Community and Public Health, Institute of Medicine. We would like to grant Nepal Health Research Council because author got data analysis and management training. The author knew details of multivariable logistic regression for example; condition of variables enter logistic regression $(P<0.2)$ after the training. The author identified details of multivariable logistic regression. Before training, author shared in different presentation without applying this criteria. We would like to acknowledge Mr. Sujit Kumar Sah who edits the language.

\section{Funding}

Dr. Hark Gurung New ERA fellowship provided some grant after the data collection of the study. The funding institution was not involved in study design, data collection, analysis and interpretation. So, the 
views of article are only of the authors.

\section{Availability of data and materials}

Data will be accessible upon request from the corresponding author.

\section{Authors' contribution}

AKS conceived the study, developed the tool, coordinated data collection, conducted the inferential analysis and drafted the manuscript. RP, MDD, and RS supported during the proposal development (Literature review, study design, methodology, ethical approval). RP also edited the language of abstract, introduction and methodology section of the manuscript. All authors have read and approved the final manuscript.

\section{Competing interests}

The abstract was presented on 6th Annual Scientific Symposium on Agriculture-Nutrition Pathways \& 25 Years of Nepal's Progress in Nutrition

The authors declare that they don't have competing interests.

\section{Consent for publication}

Not applicable.

\section{Ethical approval and consent to participate}

Ethical approval was taken from the Institutional Review Committee of Institute of Medicine, Nepal [Ref No.95 (6-11-E) 2/073/074]. Permission was taken from District Public health Office, Dhanusha. This study did not include any invasive procedure and an observational study. So, the study had no risk to study participants. Accordingly, all eligible child of mother were shared about the aim and method of the study and written Informed consent was taken. Furthermore, confidentiality was maintained and they had right to withdraw at any time from the study. 


\section{Author details}

${ }^{1}$ Department of Community Medicine and Public Health, Maharajgunj Medical Campus, Institute of Medicine, Tribhuvan University, Nepal

\section{References}

1. GoN, MoHP, DoHS, CHD. Strategy for Infant and Young Child Feeding: Nepal 2014. Ministry of Health and Population.

2. Crum J, Subedi GR, Mason J, Mebrahtu S, Dahal P. 2013. Infant and young child feeding practices as associated with child nutrition status in Nepal: Analysis of the Nepal Demographic and Health Surveys, 2011. Ministry of health of Nepal and UNICEF.

3. Chaturvedi A, Nakkeeran N, Doshi M, Patel R, Bhagwat S. Capacity of frontline ICDS functionaries to support caregivers on infant and young child feeding (IYCF) practices in Gujarat, India. Asia Pacific journal of clinical nutrition. 2014 Nov1;Suppl(23):S29-S37.

4. World Health Organization. 2014. Global Nutrition Target 2025: Stunting Policy Brief. Geneva:WHO.2014:1-6.

5. Black RE, Allen LH, Bhutta ZA, Caulfi eld LE, De Onis M, Ezzati M, Mathers C, Rivera J, Maternal and child undernutrition study group. Maternal and child undernutrition: global and regional exposures and health consequences. The lancet. 2008 Jan 19;371(9608):243-60.

6. Bhutta ZA, Das JK, Rizvi A, Gaff MF, Walker N, Horton S, Webb P, Lartey A, Black RE, Group TL, Maternal and child nutrition group. Evidence-based interventions for improvement of maternal and child nutrition: what can be done and at what cost? The Lancet. 2013 Aug 3;382(9890):452-77.

7. United Nations Children's Fund, World Health Organization, World Bank Group. Levels and trends in child malnutrition: Key findings of the 2018 Edition of the Joint Child Malnutrition Estimates.

8. Ministry of Health and Population (MOHP) [Nepal], New ERA and ICF International Inc. 2012. Nepal Demogrphic and Health Survey 2011. Kathmandu, Nepal: Ministry of Health and population, New ERA, and ICF International, Calverton, Maryland.

9. Ministry of Health Nepal, New ERA and ICF. 2017. Nepal Demographic and Health Survey 2016. Kathmandu Nepal: Ministry of Health, Nepal.

10. Pandey JP, Dhakal MR, Karki S, Poudel P and, Pradhan MS. 2013. Maternal and child ealth in Nepal: The effects of caste, ethnicity, and regional identity further analysis of the 2011 Nepal Demographic and Health Survey.Ministry of Health and Population.

11. Central Bureau of Statistics 2015. Nepal Multiple Indicator Cluster Survey 2014, final report. Kathmandu, Nepal: Central Bureau of Statistics and UNICEF Nepal.

12. Bhanderi D, Choudhary SK. An epidemiological study of health and nutritional status of under five children in semi-urban community of Gujarat. Indian journal of public health. 2006;50(4):213-9. 
13. Menon P. The crisis of poor complementary feeding in South Asia: where next? Maternal \& child nutrition. 2012 Jan;8:1-4.

14. Das S, Gulshan J. Different forms of malnutrition among under five children in Bangladesh: a cross sectional study on prevalence and determinants. BMC Nutrition. 2017 Dec;3(1):1.

15. Zongrone A, Winskell K, Menon P. Infant and young child feeding practices and child undernutrition in Bangladesh: insights from nationally representative data. Public health nutrition. 2012 Sep;15(9):1697-704.

16. Kavosi E, Rostami ZH, Kavosi Z, Nasihatkon A, Moghadami M, Heidari M. Prevalence and determinants of under-nutrition among children under six: a cross-sectional survey in Fars province, Iran. International journal of health policy and management. 2014 Jul;3(2):71-6.

17. Tariq J, Sajjad A, Zakar R, Zakar M, Fischer F. Factors associated with undernutrition in children under the age of two years: secondary data analysis based on the Pakistan demographic and health survey 2012-2013. Nutrients. 2018 Jun;10(6):676.

18. Akombi BJ, Agho KE, Merom D, Hall JJ, Renzaho A. Multilevel analysis of factors associated with wasting and underweight among children under-five years in Nigeria. Nutrients. 2017;9:44.

19. Sinha RK, Dua R, Bijalwan V, Rohatgi S, Kumar P. Determinants of stunting, wasting, and underweight in five high-burden pockets of four Indian states. Indian journal of community medicine. 2018 OctDec;43(4):279-83.

20. Asfaw M, Wondaferash M, Taha M, Dube L. Prevalence of undernutrition and associated factors among children aged between six to fifty nine months in Bule Hora district, South Ethiopia. BMC public health. $2015 \mathrm{Dec}: 15(1): 41$.

21. GoN, MoHP, DoHS. Annual Report 2014/2015: Department of Health Service, Kathmandu.

22. Government of Nepal. 2015. The Constitution of Nepal. https://www.mohp.gov.np/downloads/Constitution of Nepal 2072_full_english.pdf. Accessed 23 April 2019.

23. Sanghvi T, Haque R, Roy S, Afsana K, Seidel R, Islam S, Jimerson A, Baker J. Achieving behaviour change at scale: Alive and Thrive's infant and young child feeding programme in Bangladesh. Maternal \& child nutrition. 2016 May;12:141-54.

24. UNRCHCO. District Profile: Dhanusha. Available from: http://un.info.np/Net/NeoDocs/View/4227. Accessed 23 April 2019.

25. Charan J, Biswas T. How to calculate sample size for different study designs in medical research? Indian journal of psychological medicine. 2013 Apr;35(2):121.

26. Mekonnen TC, Workie SB, Yimer TM, Mersha WF. Meal frequency and dietary diversity feeding practices among children 6-23 months of age in Wolaita Sodo town, Southern Ethiopia. Journal of Health, Population and Nutrition. 2017 Dec; 36(1):18.

27. National Department of Health (NDoH), Statistics South Africa (Stats SA), South African Medical Research Council (SAMRC) and I 2019. South Africa Demographic and Health Survey 2016. Pretoria, South Africa, and Rockville, Maryland, USA: NDoH, Stats SA, SAMRC, and ICF. 
28. Ministry of Health (MOH) [Maldives] and ICF. 2018. Maldives Demographic and Health Survey201617. Male, Maldives, and Rockville, Maryland, USA: MOH and ICF.

29. Department of Census and Statistics (DCS) and Ministry of Health N and Indigenous Medicine 2017. Sri Lanka Demographic and Health Survey 2016 Sri Lanka.

30. Boah M, Azupogo F, Amporfro DA, Abada LA. The epidemiology of undernutrition and its determinants in children under five years in Ghana. Plos one. 2019 Jul 31;14(7):e0219665.

31. International Institute for Population Sciences (IIPS) and ICF. 2017. National Family Health Survey (NFHS-4), 2015-16: India. Mumbai: IIPS.

32. Derso T, Tariku A, Biks GA, Wassie MM. Stunting, wasting and associated factors among children aged 6-24 months in Dabat health and demographic surveillance system site: A community based cross-sectional study in Ethiopia. BMC pediatrics. 2017 Dec;17(1):96.

33. Titaley CR, Ariawan I, Hapsari D, Muasyaroh A, Dibley MJ. Determinants of the stunting of children under two years old in Indonesia: A multilevel analysis of the 2013 Indonesia basic health survey. Nutrients. 2019 May;11(5):1106.

34. Goudet SM, Griffiths PL, Bogin BA, Madise NJ. Nutritional interventions for preventing stunting in children(0 to 5 years) living in urban slums in low and middle-incomecountries (LMIC). Cochrane Database of Systematic Reviews. 2015(5).

35. Ahmad A, Madanijah S, Dwiriani CM, Kolopaking R. Complementary feeding practices and nutritional status of children 6-23 months old: formative study in Aceh, Indonesia. Nutrition Research Practice. 2018 Dec 1;12(6):512-20.

36. Lutter CK, Daelmans BM, de Onis M, Kothari MT, Ruel MT, Arimond M, Deitchler M, Dewey KG, Blossner M, Morghi E. Undernutrition, poor feeding practices, and low Coverage of key nutrition interventions. Pediatrics. 2011 Dec 1;128(6):1418-27.

37. Adhikari RK. Food utilization practices, beliefs and taboos in Nepal: an overview. United States Agency for International Development. 2010.

38. Dewey KG, Brown KH. Update on technical issues concerning complementary feeding of young children in developing countries and implications for intervention programs. Food and nutrition bulletin. 2003;24(1):5-28.

39. Sapkota VP, Gurung CK. Prevalence and predictors of underweight, stunting and wasting in under-five children. Journal of Nepal Health Research Council. 2009 Oct;7(2):120-6.

40. Neervoort F, von Rosenstiel I, Bongers K, Demetriades M, Shacola M, Wolffers I. Effect of a school feeding programme on nutritional status and anaemia in an urban slum: A preliminary evaluation in Kenya. Journal of tropical pediatrics. 2012 Dec 12;59(3):165-74

41. Sarma H, Khan JR, Asaduzzaman M, Uddin F, Tarannum S, Hasan MM, Rahman AS, Ahmed T. Factors influencing the prevalence of stunting among children aged below five years in Bangladesh. Food and nutrition bulletin. 2017 Sep;38(3):291-301.

42. Senarath U, Godakandage SS, Jayawickrama H, Siriwardena I, Dibley MJ. Determinants of inappropriate complementary feeding practices in young children in Sri Lanka: secondary data 
analysis of Demographic and Health Survey 2006-2007. Maternal \& child nutrition. 2012 Jan;8:6077.

43. Joshi N, Agho KE, Dibley MJ, Senarath U, Tiwari K. Determinants of inappropriate complementary feeding practices in young children in Nepal: secondary data analysis of Demographic and Health Survey 2006. Maternal \& child nutrition. 2012 Jan;8:45-59.

44. Jemide JO, Ene-Obong HN, Edet EE, Udoh EE. Association of maternal nutrition knowledge and child feeding practices with nutritional status of children in Calabar South Local Government Area, Cross River State, Nigeria. International journal of home science. 2016;2(1):293-8.

45. Epheson B, Birhanu Z, Tamiru D, Feyissa GT. Complementary feeding practices and associated factors in Damot Weydie District, Welayta zone, South Ethiopia. BMC Public Health. 2018 Dec;18(1):419.

46. Shahraki SH, Amirkhizi F, Amirkhizi B, Hamedi S. Household food insecurity is associated with nutritional status among Iranian children. Ecology of food and nutrition. 2016 Sep-Oct;55(5):473-90, doi: 10.1080/03670244.2016.1212710.

47. Darsene H, Geleto A, Gebeyehu A, Meseret S. Magnitude and predictors of undernutrition among children aged six to fifty nine months in Ethiopia: a cross sectional study. Archives of Public Health.2017 Dec;75(1):29.

48. Shahjada A, Sharma BK, Sharma S, Mahashabde P, Bachhotiya A. Effects of birth interval on nutritional status of under five children in periurban area of Madhya Pradesh, India. International Jornal of Medical Science Public Health. 2014 Jun1;3(6):723-7.

49. Tariku L. Effects of preceding birth intervals on child mortality in Ethiopia; Evidence from the Demographic and Health Surveys, 2016. Epidemology International Journal. 2019;3(1).

50. Rutstein SO. Effects of preceding birth intervals on neonatal, infant and under-five years mortality and nutritional status in developing countries: evidence from the demographic and health surveys. International Journal of Gynecology \& Obstetrics. 2005 Apr;89:S7-24.

51. Dewey KG, Cohen RJ. Does birth spacing affect maternal or child nutritional status? A systematic literature review. Matern \& child nutrition. 2007 Jul;3(3):151-73.

52. Senarath U, Dibley MJ. Complementary feeding practices in South Asia: Analyses of recent national survey data by the South Asia Infant Feeding Research Network. Maternal \& child nutrition. 2012 Jan;8:5-10.

\section{List Of Tables}

[Please see supplementary files to access the tables.]

Table1: Socio-demographic, economic and knowledge related characteristics of children

Table 2: Nutrition and health related characteristics of children and their mother 
Table 3: A multivariable logistic regression showing the factors associated with stunting, wasting and underweight among children aged 6-23 months in Dalit

Table 4: A multivariable logistic regression showing the factors associated with stunting, wasting and underweight among children aged 6-23 months in Non-Dalit

\section{Supplementary Files}

This is a list of supplementary files associated with this preprint. Click to download.

- Table1.xlsx

- Table3.xlsx

- Table2.xlsx

- Table4.xlsx 